370

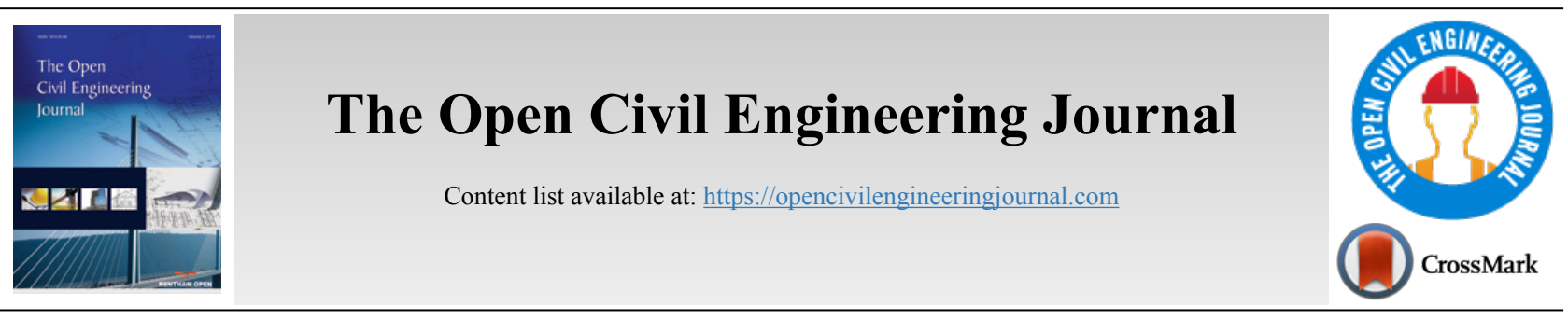

RESEARCH ARTICLE

\title{
Effect of Waste Clay Brick Powder on Physical and Mechanical Properties of Cement Paste
}

\author{
David Sinkhonde ${ }^{1, *}$, Richard Ocharo Onchiri ${ }^{2}$, Walter Odhiambo Oyawa ${ }^{3}$ and John Nyiro Mwero ${ }^{4}$ \\ ${ }^{I}$ Department of Civil and Construction Engineering, Pan African University Institute for Basic Sciences, Technology and Innovation, Nairobi, Kenya \\ ${ }^{2}$ Department of Building and Civil Engineering, Technical University of Mombasa, Mombasa, Kenya \\ ${ }^{3}$ Department of Civil, Construction and Environmental Engineering, Jomo Kenyatta University of Agriculture and Technology, Nairobi, Kenya \\ ${ }^{4}$ Department of Civil and Construction Engineering, University of Nairobi, Nairobi, Kenya
}

\begin{abstract}
:
Background:

Investigations on the use of waste clay brick powder in concrete have been extensively conducted, but the analysis of waste clay brick powder effects on cement paste is limited.

\section{Materials and Methods:}

This paper discusses the effects of waste clay brick powder on cement paste. Fragmented clay bricks were grounded in the laboratory using a ball mill and incorporated into cementitious mixes as partial replacement of Ordinary Portland Cement. Workability, consistency, setting time, density and compressive strength properties of paste mixes were investigated to better understand the impact of waste clay brick powder on the cementitious paste. Four cement replacement levels of $2.5 \%, 5 \%, 7.5 \%$ and $10 \%$ were evaluated in comparison with the control paste. The chemical and mineral compositions were evaluated using X-Ray Fluorescence and X-Ray Diffractometer, respectively. The morphology of cement and waste clay brick powder was examined using a scanning electron microscope.

Results:

The investigation of workability exhibited a reduction of slump attributed to the significant addition of waste clay brick powder into the cementitious mixes, and it was concluded that waste clay brick powder did not significantly influence the density of the mixes. In comparison with the control paste, increased values of consistency and setting time of cement paste containing waste clay brick powder confirmed the information available in the literature.

\section{Conclusion:}

Although waste clay brick powder decreased the compressive strength of cement paste, $5 \%$ partial cement replacement with waste clay brick powder was established as an optimum percentage for specimens containing waste clay brick powder following curing periods of 7 and 28 days. Findings of chemical composition, mineral composition and scanning electron microscopy of waste clay brick powder demonstrated that when finely ground, fragmented clay bricks can be used in concrete as a pozzolanic material.
\end{abstract}

Keywords: Waste clay brick powder, Cement paste, Workability, Setting time, Compressive strength, Pozzolanic materials.

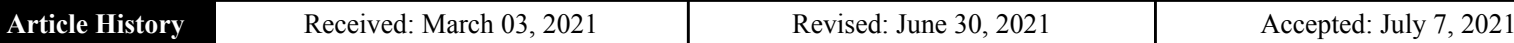

\section{INTRODUCTION}

The inclusion of pozzolanic materials in cement paste has attracted increasing interest due to its acceptable performance in compressive strength, which sometimes outweighs that of

\footnotetext{
* Address correspondence to this author at the Department of Civil and Construction Engineering, Pan African University Institute for Basic Sciences, Technology and Innovation, Nairobi, Kenya; Tel: 0748328287;

E-mail: davidsinkhonde@gmail.com
}

conventional paste. A vast amount of literature has evaluated the impact of several pozzolanic materials on cement paste, including magnetic-silica, nano-magnetic and nano-silica [1, 2], fly ash [3, 4], metakaolin [5] and silica fume [6, 7]. An exhaustive cement paste literature review undertaken has shown that the influence of Waste Clay Brick Powder (WCBP) on workability, consistency, setting time, density and compressive strength of cement paste has received little attention. Comprehensive information regarding the behaviour 
of cement paste has been repeatedly documented in the literature. Cement paste has been found to play a dominant role in the attainment of desirable concrete properties [8]. A previous investigation by other authors [9] was observed to be the most significant experimental study strongly related to this work. Their research on cement pastes revealed that WCBP considerably enhanced the demand for water for normal consistency, lowered the temperature rise during hydration, prolonged the setting time, and diminished the $\mathrm{Ca}(\mathrm{OH})_{2}$ content. From their experiments, it was reported that pozzolanic reaction exhausts $\mathrm{Ca}(\mathrm{OH})_{2}$ to generate secondary Calcium Silicate Hydrates (CSH) gels. Measurement of $\mathrm{Ca}(\mathrm{OH})_{2}$ in cementitious pastes incorporated with materials possessing pozzolanic properties was noted as evidence of pozzolanic reaction. However, this research did not investigate the effect of WCBP on the workability, density and compressive strength of cement paste.

Existing literature indicates that the use of WCBP as a partial substitute for cement offers a slight beneficial improvement in the concrete compressive strength [10, 11]. However, the mechanical performance of cement paste incorporated with WCBP is not fully explored due to limited experimental studies on the subject. The afore-mentioned research findings have demonstrated the importance of understanding the influence of WCBP on the workability, density and compressive strength of cement paste.

\section{MATERIALS AND METHODS}

\subsection{Materials}

\subsubsection{Waste Clay Brick Powder}

Waste fragmented bricks were acquired from Kenya Clay Products and were used in this experimental investigation to prepare WCBP of specific gravity of 2.69. These broken bricks were crushed using a hammer to obtain feasible particles for grinding. A small-scale ball mill of capacity 60 litres built in Mechanical Engineering Workshop at Jomo Kenyatta University of Agriculture and Technology (JKUAT) was used. It was filled with $30 \mathrm{~mm}$ steel balls and fragmented clay bricks prior to the grinding process. After the ball milling process was conducted at a speed of $1260 \mathrm{rpm}(21 \mathrm{~Hz})$ for durations of 20 , 40, 60, 80 and 100 minutes, WCBP passing through $0.075 \mathrm{~mm}$ sieve was obtained.

\subsubsection{Water}

Portable water in the Structural and Materials Laboratory at JKUAT was used in the preparation of cement paste.

\subsubsection{Cement}

Ordinary Portland Cement class 42.5 meeting the specifications for the experiments [12] and with acceptable specific gravity and Le Chatelier soundness values of 3.12 and $5.7 \mathrm{~mm}$, respectively, was used.

\subsection{Methods}

\subsubsection{Scanning Electron Microscope}

The microstructure morphology of WCBP was examined in conjunction with that of cement using high-resolution
Scanning Electron Microscope (SEM) of a $15 \mathrm{kV}$ high voltage system in JKUAT. The model for the equipment used to scan the specimens was the JEOL NeoScope JCM-7000 SEM machine. Prior to the experiment, the specimens from both materials were cleaned and dried in order to enhance surface exposure. The sprinkling of the powder and cement on the conductive adhesive tape was then conducted, followed by suitable positioning of the specimens in the equipment. The images were then captured after an accelerated electron beam penetrating through apertures and electromagnetic lenses scanned the surfaces of the specimens with the aid of scan coils.

\subsubsection{Chemical and Mineral Compositions of Cement and WCBP}

X-Ray Fluorescence (XRF) experiment was conducted using Bruker Spectrometer Gun to quantitatively explore the chemical composition of WCBP. This test was conducted at the Ministry of Petroleum and Mining in Nairobi, Kenya. An XRF gun is often used for this elemental analysis due to its versatility of characterisation techniques in addition to its ability to outperform other methods with regard to the economical value [12]. The test employs a voltage of 30-60 kV and a current of 50-100 mA. Typical elemental compositions of cement were also examined for comparison. In addition, an XRay Diffractometer (XRD) analysis of cement and WCBP was conducted on a diffractometer (Bruker D2 Phaser) equipped with a graphite monochromator. Commercially available software packages of Defrac Eva and Defrac Suite were employed as scan software and match software, respectively.

\subsubsection{Cement Pastes}

Four cement pastes were prepared by partially substituting the weight of cement with $2.5 \%, 5 \%, 7.5 \%$ and $10 \%$ of WCBP. A control cement paste without WCBP was also prepared for comparison. The proportions of all the paste ingredients as per mix design are illustrated in Table $\mathbf{1}$. The preparations of paste for assessment were carried out in two phases. The first phase constituted cement paste preparation for the determination of workability, density and compressive strength. The mixing procedure included manual mixing of cement with water for all mixes. This used a water/binder ratio of 0.42 for approximately 10 minutes. This was consistent with another author's work [13].

Table 1. Mix design for cement/WCBP paste mixtures.

\begin{tabular}{|c|c|c|c|}
\hline \multirow{2}{*}{ Sample } & \multicolumn{2}{|c|}{ Mix Proportions (\%) } & \multirow{2}{*}{ W/B } \\
\cline { 2 - 3 } & Cement & Brick Powder & \\
\hline BP-00P & 100 & 0 & 0.42 \\
\hline BP-2.5P & 97.5 & 2.5 & 0.42 \\
\hline BP-5.0P & 95 & 5 & 0.42 \\
\hline BP-7.5P & 92.5 & 7.5 & 0.42 \\
\hline BP-10P & 90 & 10 & 0.42 \\
\hline
\end{tabular}

The second phase tested the influence of WCBP on consistency and setting times of cement paste. The specimen descriptions to establish the influence of material replacement levels were BP-00P, BP-2.5P, BP-5.0P, BP-7.5P and BP-10P, accurately labeled to reflect the percentage replacements of 
cement by WCBP.

\subsubsection{Slump Test}

Slump test was carried out in conformity with the code. A slump cone with dimensions of $30 \mathrm{~cm}$ height, $10 \mathrm{~cm}$ top diameter, $20 \mathrm{~cm}$ bottom diameter and metal thickness of 1.60 $\mathrm{mm}$ was used.

\subsubsection{Standard Consistency}

The experimental procedures for standard consistency of cement paste incorporated with WCBP were carried out according to specifications in the code. A Vicat apparatus consisting of a $10 \mathrm{~mm}$ plunger and a Vicat mould resting on a non-porous plate was used to carry out the test.

\subsubsection{Setting Times}

Initial and final setting times of cement paste containing WCBP were determined in compliance with specifications in the code. A Vicat apparatus with a needle for the initial set and a needle with attachment for the final set was used.

\subsubsection{Density}

The densities were determined after 7 and 28 days of curing periods in accordance with specifications in the code. A balance calibrated to an accuracy of $0.1 \%$ was used for the measurement of mass.

\subsubsection{Compressive Strength}

Measurements of the paste compressive strengths were conducted for 7 and 28 days curing periods using $70 \times 70 \times 70$ $\mathrm{mm}$ and $100 \times 100 \times 100 \mathrm{~mm}$ cube specimens in accordance with specifications in the code. Besides, prismatic specimens of dimensions of $40 \times 40 \times 160 \mathrm{~mm}$ were prepared to capture prismatic compressive strength in accordance with the code. The tests were performed using a $1500 \mathrm{kN}$ capacity universal testing machine with a Servo-Plus evolution control unit.

\section{RESULTS AND DISCUSSION}

\subsection{Scanning Electron Microscope}

Figs. (1 and 2) show images captured using SEM technique for cement and WCBP, respectively. The SEM method was used to study typical particle surface texture and shape of the particles. This method is sufficiently capable to examine the morphology, formation, size and size distribution of materials by probing the specimen on fine scaling $[14,15]$.

Image analysis using the ImageJ program revealed the average nanoparticle lengths of $522 \mathrm{~nm}$ and $1034 \mathrm{~nm}$ for WCBP and cement, respectively, at a scale bar of $10 \mu \mathrm{m}$. However, it is important to note that separating individual particles using ImageJ is difficult due to the tendency of nanoparticles to agglomerate [16]. Thus, evaluating nanoparticle size distribution with desirable accuracy is a major challenge. It is evident from Fig. (2) that WCBP particles in this study are neither smooth nor spherical. Nevertheless, the particles demonstrate irregular and sharp corners which are observed to formulate slits. Finer particles are observed to abide in the slits and notches of bigger sizes when the particles are subjected to higher levels of magnification. Accordingly, this peculiar arrangement enhances the water demand and impedes the workability characteristics of fresh concrete [17]. SEM images captured for WCBP visibly reveal finer particles in comparison with SEM images of cement. It is known that finer brick powder absorbs more water resulting in a reduced slump and increased consistency of cement paste [18]. Previously, other authors [19] have also indicated that finer particles of WCBP are responsible for influencing the early age hydration, a phenomenon which is attributed to the formation of crystallisation nucleus which enhances the propagation of hydrated products. Using WCBP in cement paste and in concrete is therefore suggested to achieve a reduced slump and early strength of cement paste and concrete.

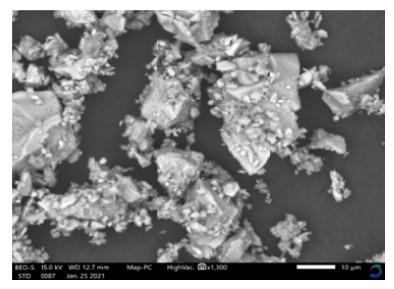

(a) Scale bar: $10 \mu \mathrm{m}$

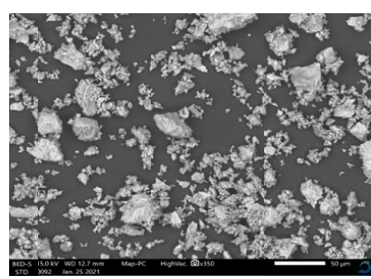

(c) Scale bar: $50 \mu \mathrm{m}$

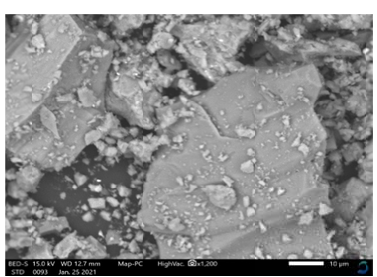

(a) Scale bar: $10 \mu \mathrm{m}$

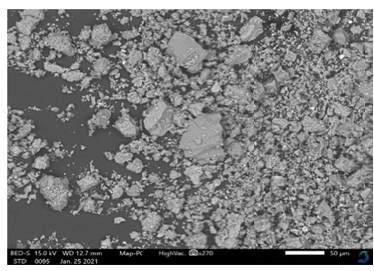

(c) Scale bar: $50 \mu \mathrm{m}$
Fig. (1). SEM images of cement.

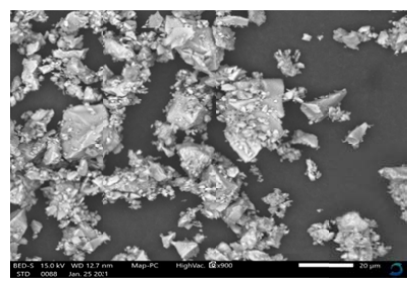

(b) Scale bar: $20 \mu \mathrm{m}$

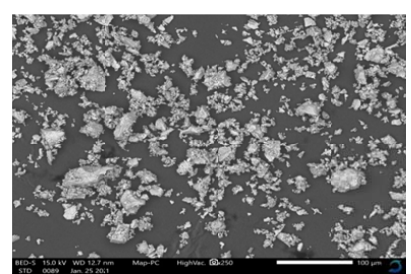

(d) Scale bar: $100 \mu \mathrm{m}$

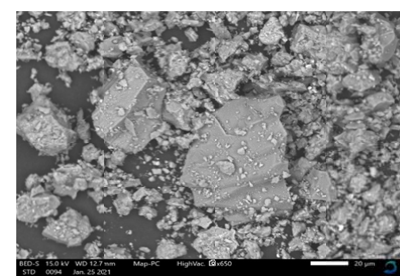

(b) Scale bar: $20 \mu \mathrm{m}$

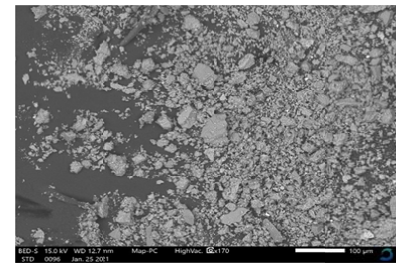

(d) Scale bar: $100 \mu \mathrm{m}$

Fig. (2). SEM images of WCBP.

\subsection{Chemical and Mineral Compositions}

\subsubsection{Chemical Composition}

Table 2 lists the chemical compositions present in cement and WCBP. The table compares the amounts of each chemical in cement and WCBP. As shown in the table, all oxides 
quantified in cement are also visible in WCBP. $62.45 \%$ of $\mathrm{CaO}$ in cement and $64.36 \%$ of $\mathrm{SiO}_{2}$ are consistent with other research works [20], and pronounced pozzolanic reaction is expected once the cement is mixed with WCBP. In addition, the absence of $\mathrm{MgO}$ in cement is observed to lead to acceptable soundness properties [21].

Table 2 shows that the dominant chemical components in WCBP are $\mathrm{SiO}_{2}, \mathrm{Fe}_{2} \mathrm{O}_{3}$ and $\mathrm{Al}_{2} \mathrm{O}_{3}$. A computed sum of the percentages of these 3 elements is $85.93 \%$ which constitutes over $70 \%$ of the entire weight of the WCBP. The loss on ignition was also found to be negligible at $0.97 \%$. Interestingly, after knowing these general properties, it can be deduced that WCBP is fully compliant with the code [22] as a pozzolanic material, and can react with $\mathrm{Ca}(\mathrm{OH})_{2}$ upon the commencement of hydration reaction. The standard prescribes that class $\mathrm{N}$ pozzolans exhibit a minimum value of $\left(\mathrm{SiO}_{2}+\mathrm{Fe}_{2} \mathrm{O}_{3}+\mathrm{Al}_{2} \mathrm{O}_{3}\right)$ and maximum loss on ignition of $70 \%$ and $10 \%$, respectively.
The pozzolanic characteristics demonstrated by the levels of $\mathrm{SiO}_{2}, \mathrm{Fe}_{2} \mathrm{O}_{3}$ and $\mathrm{Al}_{2} \mathrm{O}_{3}$ in WCBP suggest the potential usage of brick powder from fragmented clay bricks as a cement substitute in sustainable construction.

\subsubsection{Mineral Composition}

Figs. (3 and 4) illustrate the XRD patterns of cement and WCBP, respectively. The figures show maximum peak locations for cement and WCBP ranging from $26^{\circ}$ to $30^{\circ} 2$ theta degrees. In Tables 3 and 4, mineral compositions of cement and WCBP, respectively, are presented to facilitate spectra interpretation. The presence of gypsum and lime in large contents, as shown in Fig. (3), is an evidence of cement with superior properties which is likely to contribute to the pozzolanic activity. The amorphous component of WCBP which substantially determines the pozzolanic reaction according to other authors [23] is represented in Fig. (4) by a large characteristic hump at $2 \theta$ degree of $27.2^{\circ}$.

Table 2. The chemical composition of cement and WCBP.

\begin{tabular}{|c|c|c|c|c|c|c|c|c|c|c|c|c|c|}
\hline Material & $\mathrm{SiO}_{2}$ & $\mathrm{Fe}_{2} \mathrm{O}_{3}$ & $\mathrm{Al}_{2} \mathrm{O}_{3}$ & $\mathrm{CaO}$ & MgO & $\mathrm{Na}_{2} \mathrm{O}$ & $\mathrm{K}_{2} \mathrm{O}$ & $\mathrm{TiO}_{2}$ & MnO & $\mathbf{P}_{2} \mathbf{O}_{5}$ & Ba & $\mathbf{S}$ & LOI \\
\hline Cement & 15.45 & 4.55 & 2.81 & 62.45 & - & 0.48 & 1.01 & 0.47 & 0.12 & 1.29 & 0.05 & 2.75 & 7.47 \\
\hline WCBP & 64.36 & 12.86 & 8.71 & 2.00 & - & 1.82 & 3.05 & 2.13 & 0.68 & 1.18 & 1.18 & - & 0.97 \\
\hline
\end{tabular}

-Not detected.

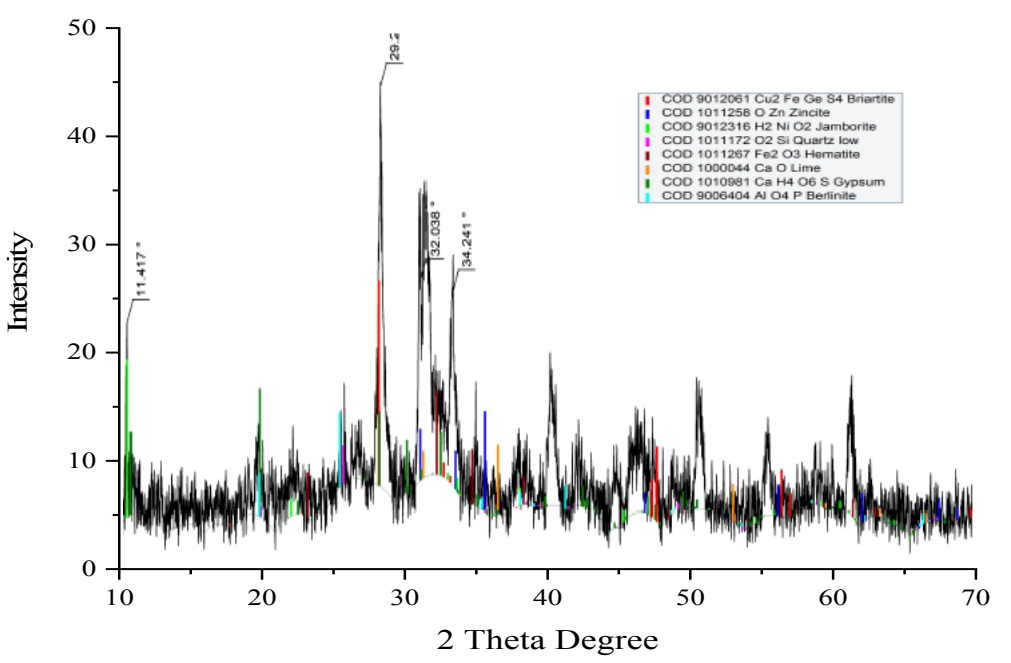

Fig. (3). The mineral composition of cement based on the XRD spectrum.

Table 3. The mineral composition of cement generated from XRD.

\begin{tabular}{|c|c|c|c|c|}
\hline Compound Name & Formula & Pattern \# & I/Ic DB & S-Q (\%) \\
\hline Gypsum & $\mathrm{CaSO}_{4} \cdot 2 \mathrm{H}_{2} \mathrm{O}$ & COD 1010981 & 2.070 & 39.5 \\
\hline Briartite & $\mathrm{Cu}_{2} \mathrm{FeGeS}_{4}$ & COD 9012061 & 9.800 & 13.3 \\
\hline Hematite & $\mathrm{Fe}_{2} \mathrm{O}_{3}$ & COD 1011267 & 4.830 & 11.1 \\
\hline Zincite & $\mathrm{ZnO}$ & COD 1011258 & 6.960 & 9.3 \\
\hline Lime & $\mathrm{CaO}$ & COD 1000044 & 4.840 & 9.2 \\
\hline Berlinite & $\mathrm{AlPO}_{4}$ & COD 9006404 & 6.390 & 7.5 \\
\hline Quartz low & $\mathrm{SiO}_{2}$ & COD 1011172 & 6.640 & 5.3 \\
\hline Jamborite & $\mathrm{Ni(OH})_{2}$ & COD 9012316 & 21.840 & 4.7 \\
\hline
\end{tabular}




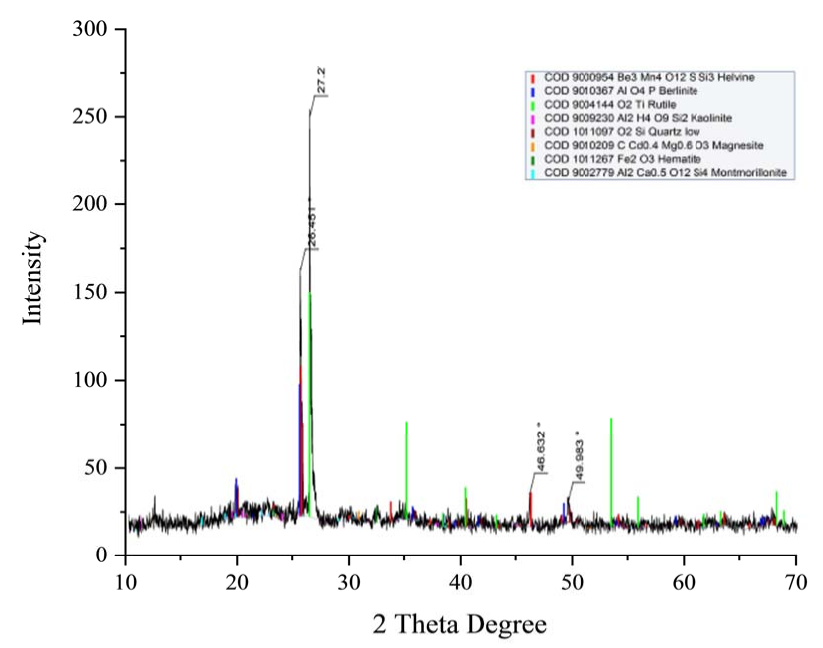

Fig. (4). The mineral composition of WCBP based on the XRD spectrum.

Table 4. The mineral composition of WCBP generated from XRD.

\begin{tabular}{|c|c|c|c|c|}
\hline Compound Name & Formula & Pattern \# & I/Ic DB & S-Q (\%) \\
\hline Rutile & $\mathrm{TiO}_{2}$ & COD 9004144 & 3.730 & 35.1 \\
\hline Helvine & $\mathrm{Mn}_{4} \mathrm{Be}_{3}\left(\mathrm{SiO}_{4}\right)_{3} \mathrm{~S}$ & COD 9000954 & 4.840 & 18.1 \\
\hline Berlinite & $\mathrm{AlPO}_{4}$ & COD 9010367 & 4.530 & 17.1 \\
\hline Quartz low & $\mathrm{SiO}_{2}$ & COD 1011097 & 4.430 & 12.3 \\
\hline Montmorillonite & $\mathrm{Al}_{2} \mathrm{Ca}_{0.5} \mathrm{SiO}_{12}$ & COD 9002779 & 20.500 & 8.2 \\
\hline Kaolinite & $\mathrm{Al}_{2} \mathrm{Si}_{2} \mathrm{O}_{5}(\mathrm{OH})_{4}$ & COD 9009230 & 1.220 & 6.1 \\
\hline Hematite & $\mathrm{Fe}_{2} \mathrm{O}_{3}$ & COD 1011267 & 4.830 & 1.8 \\
\hline Magnetise & $\mathrm{MgCO}_{2}$ & COD 9010209 & 4.140 & 1.2 \\
\hline
\end{tabular}

The peak intensities in XRD analysis reveal an estimated quantity of compounds available in the specimen [24]. The presence of gypsum in cement and silicates in WCBP is associated with the creation of $\mathrm{CSH}$ which contributes to strength. Crucial mineral constituents in WCBP, including Rutile $\left(\mathrm{TiO}_{2}\right)$, Helvine/Helvite $\left(\mathrm{Mn}_{4} \mathrm{Be}_{3}\left(\mathrm{SiO}_{4}\right)_{3} \mathrm{~S}\right)$, Berlinite $\left(\mathrm{AlPO}_{4}\right)$, Quartz low $\left(\mathrm{SiO}_{2}\right)$ and Montmorillonite $\left(\mathrm{Al}_{2} \mathrm{Ca}_{0.5} \mathrm{SiO}_{12}\right)$, are shown in Table 4 , and these are unsurprising compounds in clay bricks. It is worth noting that $\mathrm{SiO}_{2}$ is a principal compound detected in the spectrum for several mineral compounds and is strongly associated with pozzolanic activity $[25,26]$, whereas $\mathrm{CaCO}_{3}$ is observed to contribute to the hydration of $\mathrm{C}_{3} \mathrm{~A}$ to produce monocarboaluminate $\left(\mathrm{C}_{3} \mathrm{~A} \_\mathrm{CaCO}_{3}{ }_{-} 11 \mathrm{H}_{2} \mathrm{O}\right)$ [27]. The formation of calcium monocarbonalumate takes place due to $\mathrm{C}_{3} \mathrm{~A}$ and carbonate ions reaction as mentioned by several researchers [28, 29]. Additionally, among the compounds is $\mathrm{TiO}_{2}$ which is found to enhance the mechanical strength of concrete [30].

\subsection{Workability of Cement Paste}

Fig. (5) illustrates the measured slump values plotted against the corresponding WCBP values for the investigated mixtures. As the figure indicates, increasing the amount of
WCBP yielded a significant reduction in the slump with a constant water-binder ratio of 0.42 . Importantly, the decreased workability due to the inclusion of WCBP in cementitious paste resembles the cases of concrete and mortar reported in previous studies [31, 32].

Reduction in slump might be explained by high specific area of WCBP [33]. It is explicit that the mixtures were stiffer as the quantity of WCBP increased for a constant water-binder ratio. These empirical results suggest that slump reduction was attributable to the introduction of WCBP observed to possess a rough surface [18]. This is also evident in SEM results presented in Section 3.1. It should be noted that for a constant water-binder ratio, smaller sizes of WCBP are less workable than larger sizes [34]. Therefore, low workability was attributed to higher levels of wetting of large surface area caused by inclusion of WCBP.

\subsection{Consistency}

The standard consistency expressed as a percentage of water at distinctive partial cement replacements is plotted in Fig. (6). As illustrated in this figure, the increase in WCBP accounted for the increase in standard consistency compared to the control cement paste. 


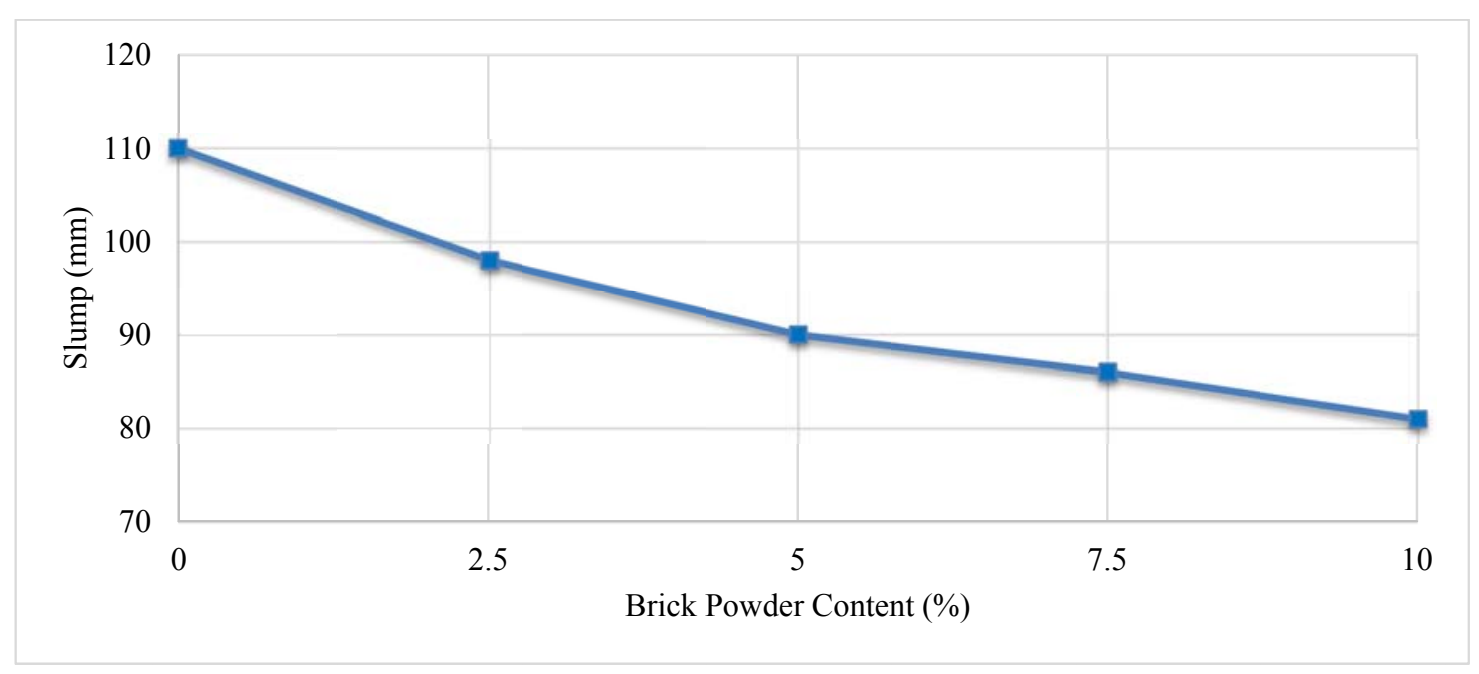

Fig. (5). Relation between slump and pastes having different brick powder contents.

The results showed that cement paste consistency increased with the increase in WCBP. It was noted that cement paste containing WCBP lacked water in an attempt to attain a plunger penetration of $6 \pm 2 \mathrm{~mm}$ from the lower side of Vicat mould, thereby generating a demand for water. These findings are in agreement with other researchers [9], who observed that $25 \%$ cement replacement with ground clay brick powder increased the normal consistency of cement paste by $4 \%$ compared to control paste.

Consistency implies the fluidity and mobility or resistance to shear deformation of cement paste [35]. Generally, consistency plays a crucial role in depicting the workability characteristics of concrete [36]. It is clear that findings of consistency for cement paste premixed with WCBP resembled those of workability presented in Section 3.3. From both experiments, the demand for water was significantly enhanced due to the incorporation of WCBP in cement paste. The high surface area of ground clay bricks partially substituting cement has been found to result in increased water demand [33]. Metakaolin has also been known to increase the consistency of cementitious paste mixes due to its high surface area [37].

\subsection{Setting Time}

Fig. (7) shows the trends of initial and final setting times of cement paste. The figure reveals the influence of WCBP on the initial and final setting times of cement paste. As anticipated, the initial and final setting times for cement paste containing WCBP were clearly greater than those for control cement paste.

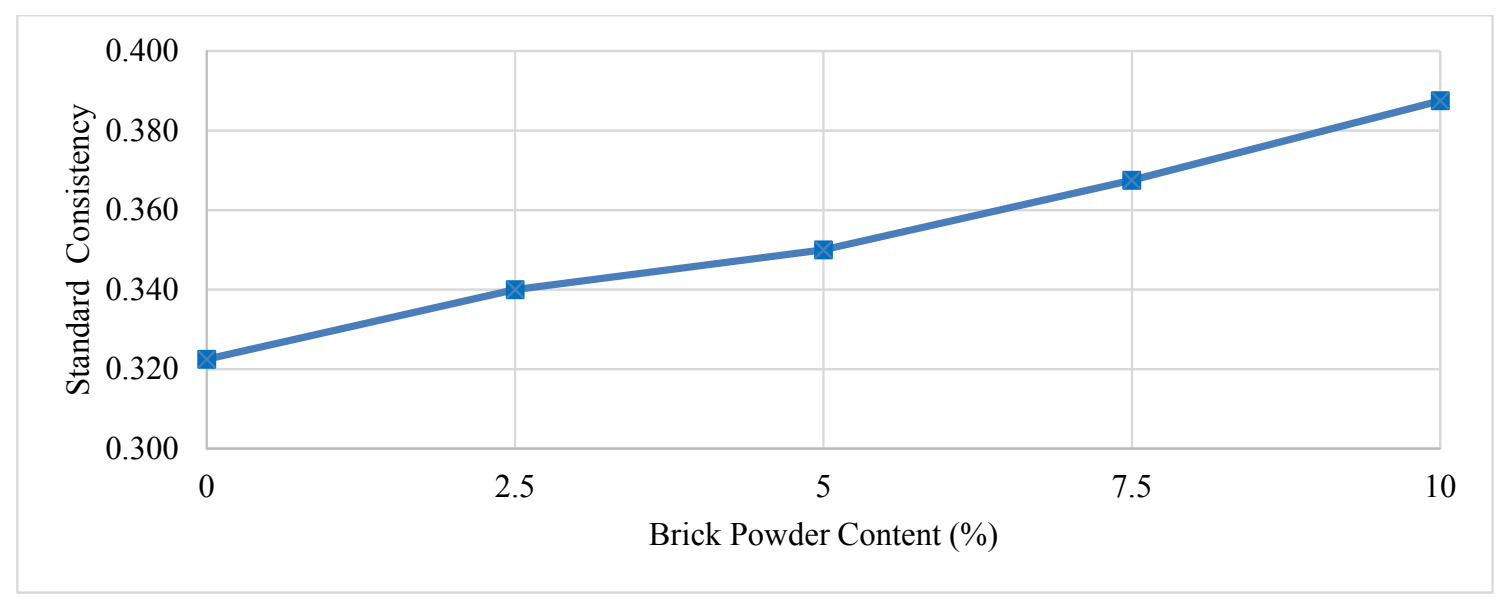

Fig. (6). Influence of WCBP on the consistency of cement paste. 


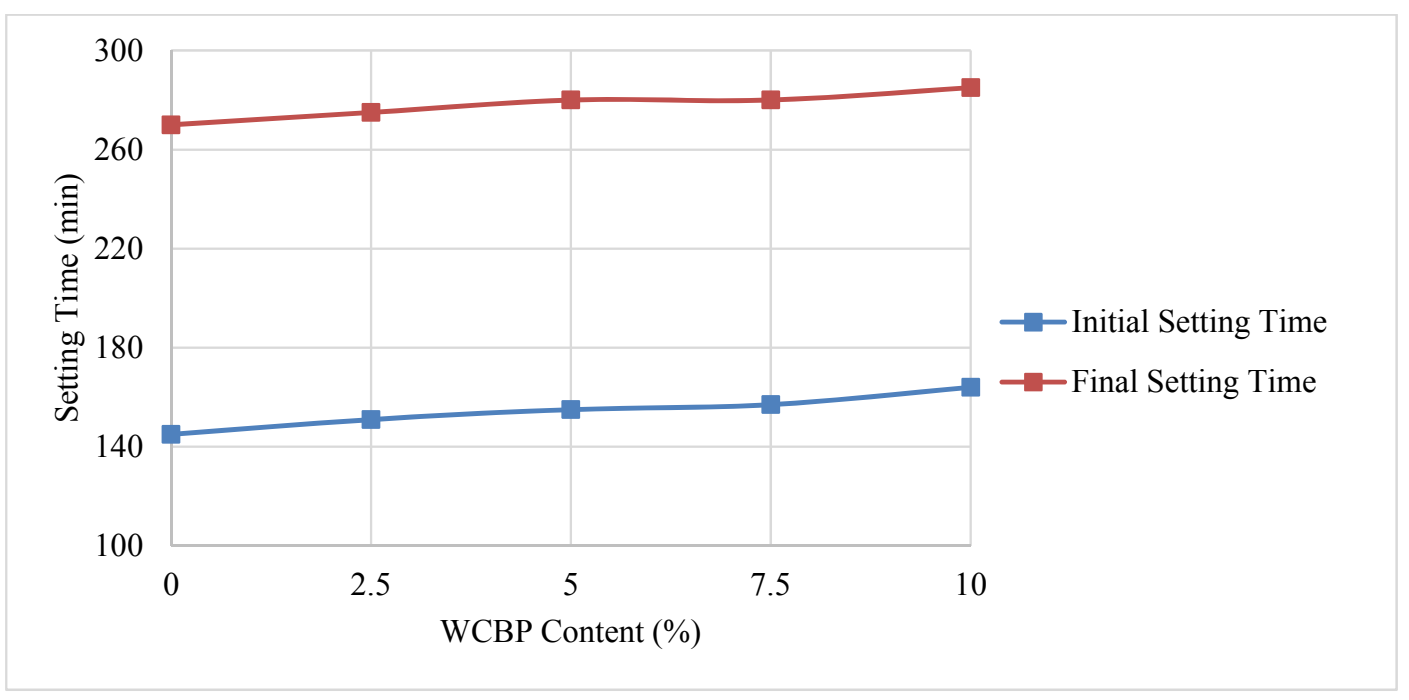

Fig. (7). Effect of WCBP on setting times of cement paste.

The content of $\mathrm{SiO}_{2}$ in clay bricks is observed to possess porous structures which prolong the setting times [38]. According to these authors, porous structures have a detrimental effect on the degree of stiffening of cement paste which prolongs setting times. In addition, $\mathrm{Fe}_{2} \mathrm{O}_{3}, \mathrm{Na}_{2} \mathrm{O}$ and $\mathrm{K}_{2} \mathrm{O}$ are also thought to increase the setting times [39]. WCBP in this study contained $\mathrm{SiO}_{2}, \mathrm{Fe}_{2} \mathrm{O}_{3}, \mathrm{~K}_{2} \mathrm{O}$ and $\mathrm{Na}_{2} \mathrm{O}$ at $64.36 \%$, $12.86 \%, 3.05 \%$ and $1.82 \%$, respectively. This might be the cause for the increased setting times. The findings in this study suggest that the increase in setting times due to the incorporation of WCBP was attributed to the predominant amount of $\mathrm{SiO}_{2}$.

\subsection{Density of Cement Paste}

Figs. (8 and 9) illustrate the influence of WCBP on the density of cement paste. These figures seem to indicate that cement paste with WCBP showed similar densities compared to the control mix, regardless of the substitution levels of WCBP. The densities computed using cubes of $100 \times 100 \times$ $100 \mathrm{~mm}$ dimensions ranged from 1900 to $2100 \mathrm{~kg} / \mathrm{m}^{3}$ for both curing periods. The results are in close agreement with other researchers [18], who reported similar densities for concrete containing WCBP in comparison with normal concrete.

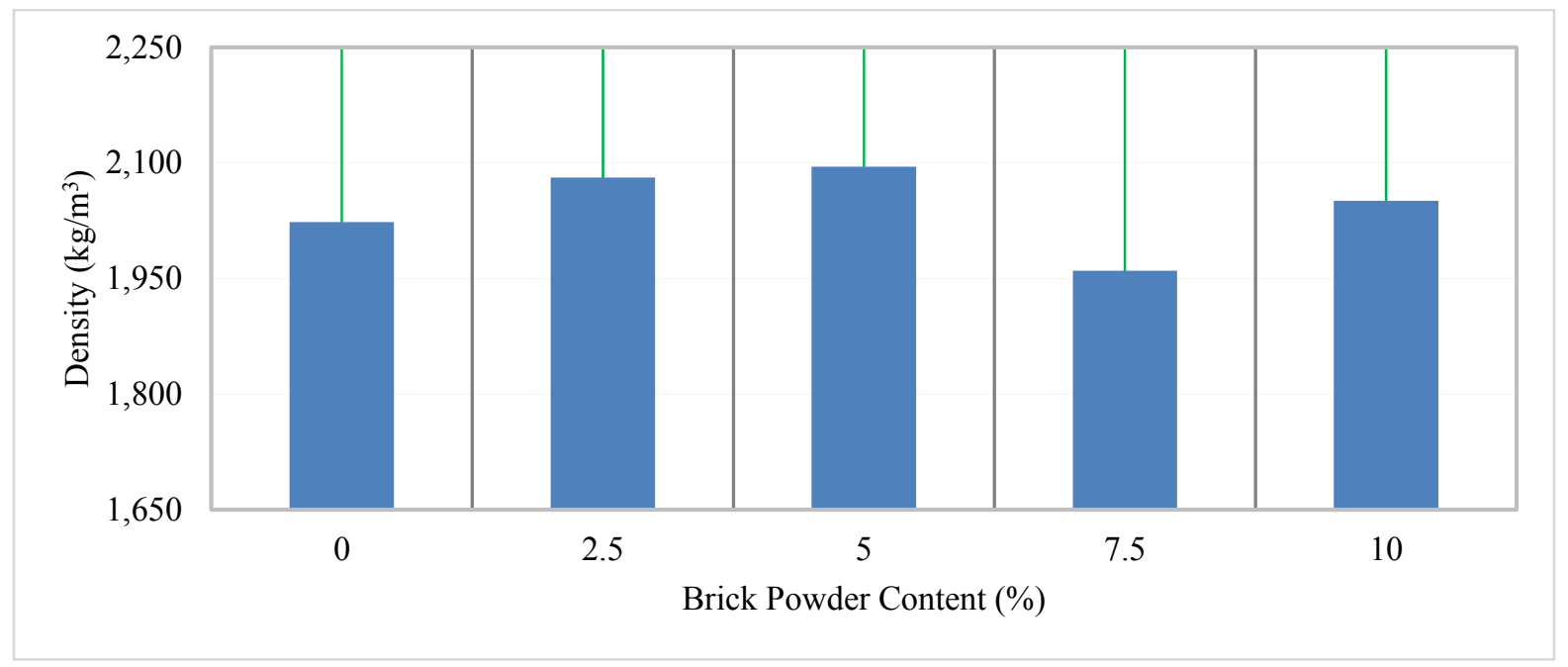

Fig. (8). Effect of WCBP on the density of cement paste cubes after 7 days curing period. 


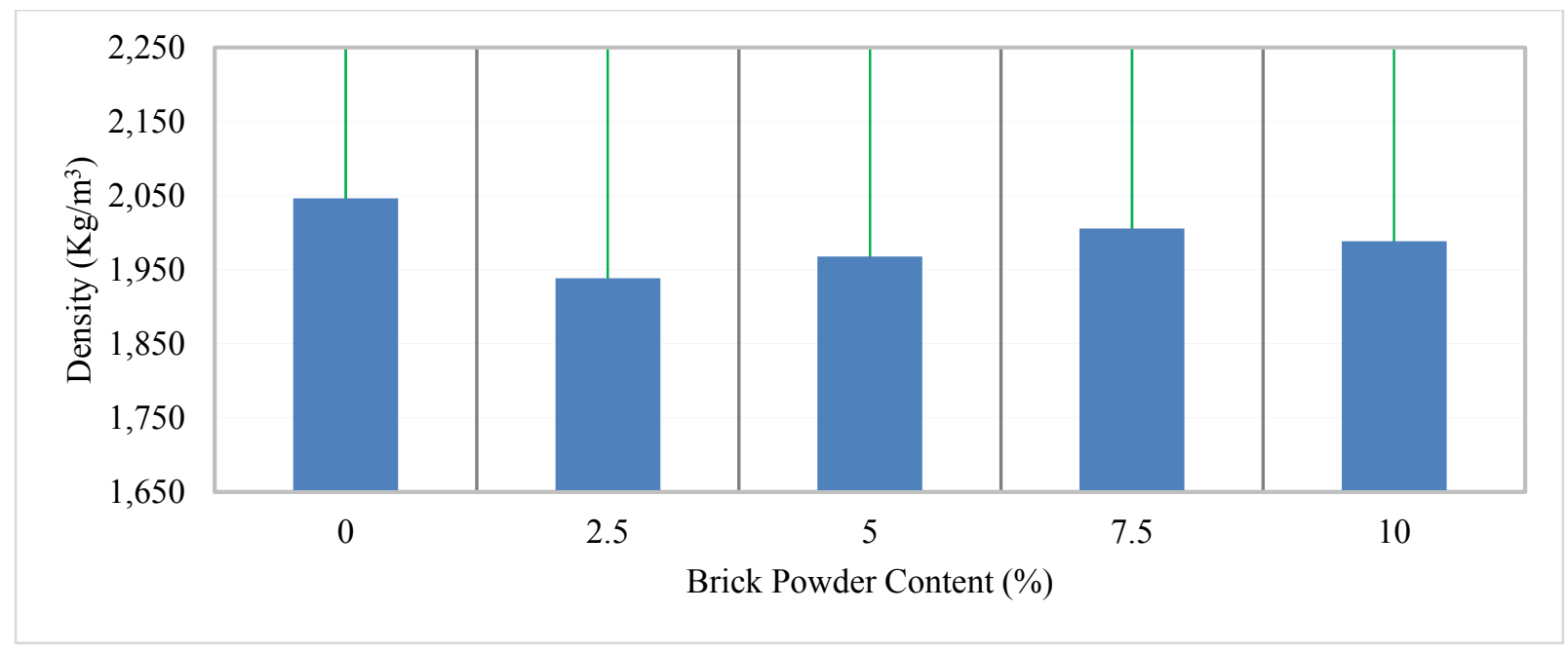

Fig. (9). Effect of WCBP on the density of cement paste cubes after 28 days curing period.

Based on the aforementioned findings, it can be concluded that there was no impact of WCBP on the density of cement paste as all cement pastes displayed similar densities. The phenomenon of packing density can be suggested to have contributed to similar densities observed in this study. Packing density, defined as the ratio of solid particle volume to bulk particle volume, is an essential value influencing the behaviour of various cementitious materials [40]. Other researchers [41] revealed that brick powder did not change the packing density of cement paste in comparison with the control paste. The Compressible Packing Model employed by these authors also showed similar packing densities of cement paste in the presence and the absence of brick powder. It was highlighted that this occurred despite cement having a higher density than brick powder. Using this line of reasoning, it is expected that cement paste incorporated with WCBP would result in densities similar to reference paste.

\subsection{Compressive Strength of Cement Paste}

Compressive strength tests were conducted on paste incorporated with WCBP, and the results at 7 days and 28 days curing periods are summarised in Figs. (10 and 11) respectively. The experimental findings demonstrated that in the presence of WCBP, the compressive strength of paste decreased compared to paste in the absence of WCBP (Control). By referring to the control paste, the cube compressive strength after 7 days curing (Fig. 10) decreased by $48.5,40.1,40.4$ and $51.4 \%$ for $2.5,5,7.5$ and $10 \%$ partial cement replacements by WCBP, respectively. A similar pattern was observed for cube compressive strength after 28 days of curing (Fig. 11), in which there was a reduction in compressive strength by $27.3,14.9,33.1$ and $48.8 \%$ for $2.5,5,7.5$ and $10 \%$ WCBP replacements, respectively.

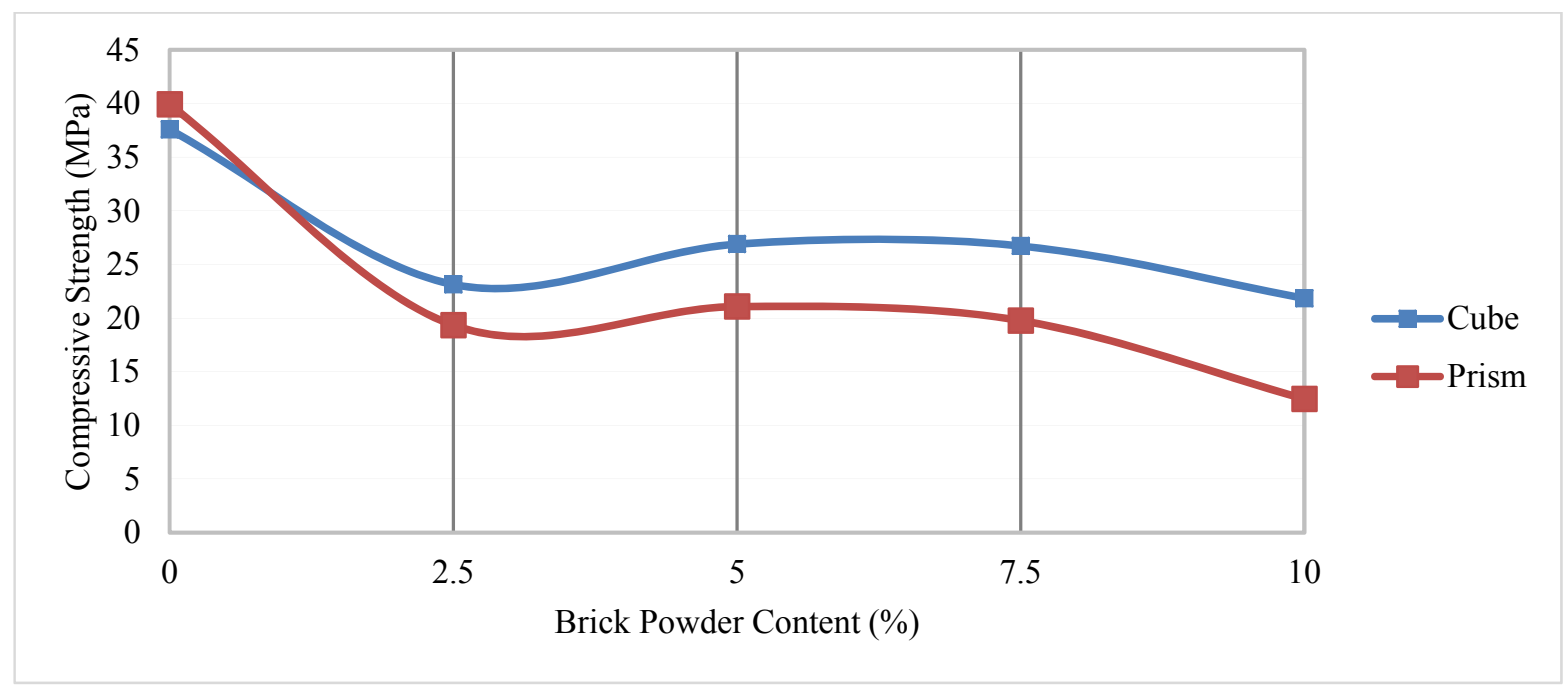

Fig. (10). The effect of WCBP content on compressive strength of cement paste after 7 days curing period. 


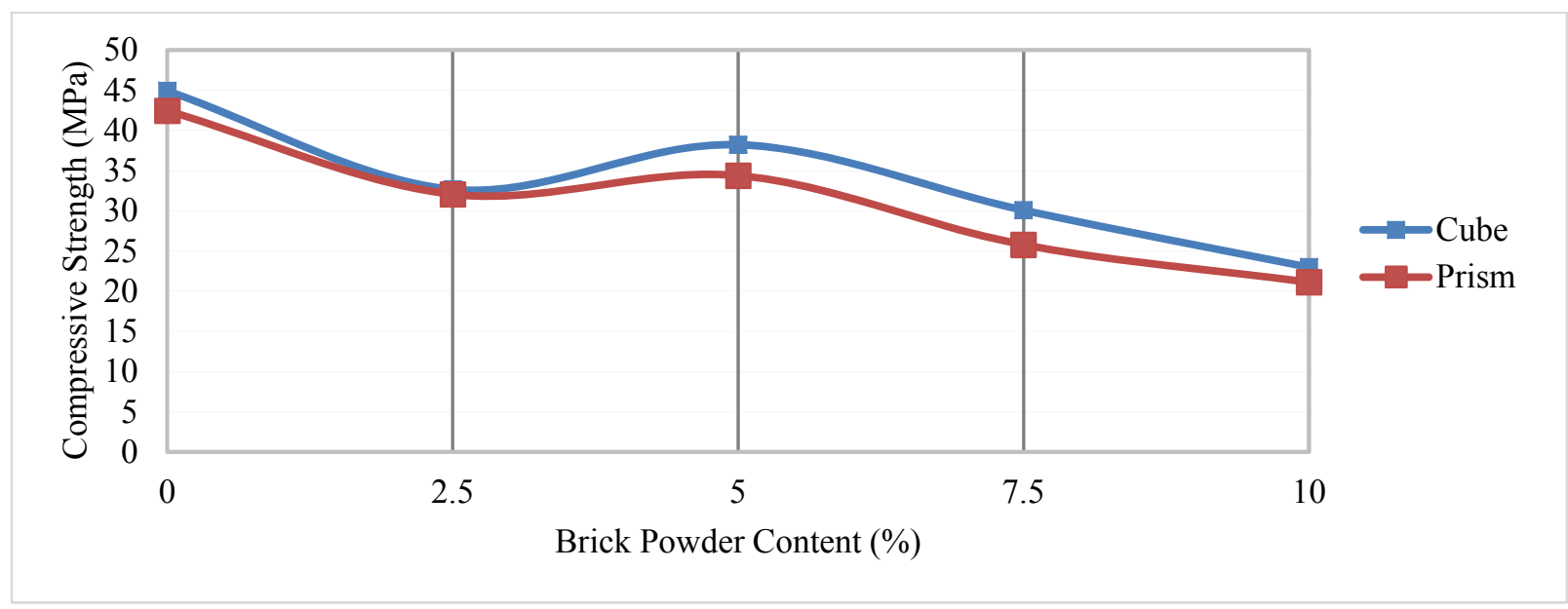

Fig. (11). The effect of WCBP content on compressive strength of cement paste after 28 days curing period.

Cement pastes with WCBP showed reduced compressive strengths compared to the control paste at the constant waterbinder ratio for both 7 and 28 days samples. It can be seen that pozzolanic activity occurred in the course of 28 days curing period which consequently led to increased compressive strength values. WCBP partially substituting cement in other investigations $[10,11,30]$ showed a slight increase in concrete compressive strength for 28 days curing duration. This leads to a controversy as to why WCBP partially replacing cement in cement paste shows no increase in compressive strength compared to control paste but rather a slight increase in concrete for the same curing period. For the latter, this behaviour was assigned to the strengthening of the bonds between aggregate and cement paste [7]. It is clear that WCBP in this study did not show strengthening effects resulting in increased compressive values compared to control paste. Slow pozzolanic reactions of WCBP which require a longer period to attain complete reaction could be suggested as the cause of such behaviour $[42,43]$.

Although compressive strengths of all prism specimens incorporated with WCBP were less than that of control paste, there was a noticeable improvement in compressive strength of paste containing 5\% WCBP for prism specimens at the end of 7 and 28 days curing periods. Also, 28 days cube specimens containing WCBP revealed 5\% optimal cement replacement in cement paste. However, the 7 days trend of cube specimens incorporated with WCBP seems to show the optimum value to be between $5 \%$ and $7.5 \%$. This lack of agreement with the other three trends might be attributed to a possible error. The pozzolanic action of WCBP seemed to increase the compressive strength from $2.5 \%$ to $5 \%$ cement replacement levels. Suggested interpretation can be the clinker amount effect [5]. The researchers reasoned that the high availability of $\mathrm{Ca}(\mathrm{OH})_{2}$ in cement leads to an increased reactivity rate with $\mathrm{SiO}_{2}$ in cement paste and this might be the cause of increased strength. There was a decrease in compressive strength beyond $5 \%$ cement replacement by WCBP. An increment in the percentage of WCBP might have potentially caused the matrix microstructure to be heterogeneous, thereby resulting in reduced compressive strength values $[1,43]$. Clinker dilution effect due to an increase in pozzolanic materials could also be suspected to have led to reduced strength [5]. This is mainly evident in low curing periods as is the case in this study due to reduced levels of $\mathrm{Ca}(\mathrm{OH})_{2}$ to react with $\mathrm{SiO}_{2}$ [5]. Nevertheless, meaningful discussion on pozzolanic reaction could be enhanced with older samples.

\section{CONCLUSION}

The following conclusions are derived from the findings reported in this paper:

(a) This research proved that WCBP acquired from waste clay bricks can be used as a pozzolan in cement paste.

(b) The addition of WCBP reduced the workability of mixtures. However, the workability findings demonstrated the potential applicability of cement paste containing WCBP in rigid pavements where fresh cement paste retains its shape.

(c) The effects of WCBP on consistency and setting times of cement paste are similar. The addition of WCBP can increase the consistency and setting times of cementitious paste.

(d) Changes in WCBP content did not significantly affect the density of mixtures.

(e) Replacement of cement by WCBP in cement paste decreases compressive strength. Meanwhile, using WCBP could develop sustainable cement paste for binding applications between old and new concrete, grouting and filling of cavity holes.

(f) Compressive strength of cement pastes containing WCBP reached its maximum value at $5 \%$ partial cement replacement by WCBP at both 7 and 28 days.

Additional tests of flexural strength and Young's modulus are recommended in an effort to evaluate the influence of WCBP on other mechanical properties of cement paste. Moreover, the effect of WCBP on the mechanical properties of cement paste for longer curing periods should be investigated. 
A deeper understanding of the pozzolanic reaction of WCBP could be achieved by increasing curing duration.

\section{LIST OF ABBREVIATIONS}

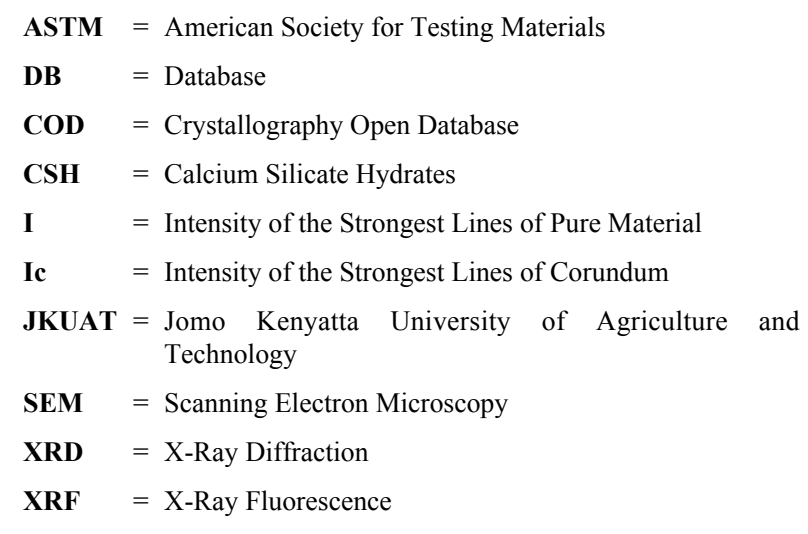

\section{CONSENT FOR PUBLICATION}

Not applicable.

\section{AVAILABILITY OF DATA AND MATERIALS}

Not applicable.

\section{FUNDING}

This research was funded by the African Union Commission as a contribution to higher education in Africa through Pan African University (Grant no. 10.13039/501100004532).

\section{CONFLICT OF INTEREST}

The authors declare no conflict of interest, financial or otherwise.

\section{ACKNOWLEDGEMENTS}

The authors sincerely thank the Pan African University for the provision of research funds. The authors additionally thank the employees at the Kenya Ministry of Petroleum and Mining for granting permission to use XRF and XRD equipment. The authors also express their profound gratitude to the Jomo Kenyatta University of Agriculture and Technology for the provision of laboratory equipment and technical staff throughout this research.

\section{REFERENCES}

[1] M. Bolhassani, and M. Sayyahmanesh, "A study on mechanical properties of cement paste using magnetite-silica nano-composites", Adv. Cement Res., vol. 27, no. 10, pp. 571-580,

[http://dx.doi.org/10.1680/jadcr.14.00106]

[2] M. Berra, F. Carassiti, T. Mangialardi, A.E. Paolini, and M. Sebastiani, "Effects of nanosilica addition on workability and compressive strength of Portland cement pastes", Constr. Build. Mater., vol. 35, no. 2, pp. 666-675, 2012. [http://dx.doi.org/10.1016/j.conbuildmat.2012.04.132]

[3] A. Ehsani, M. Nili, and K. Shaabani, "Effect of nanosilica on the compressive strength development and water absorption properties of cement paste and concrete containing Fly Ash", KSCE J. Civ. Eng., vol. 21, no. 5, pp. 1854-1865, 2017. [http://dx.doi.org/10.1007/s12205-016-0853-2]

[4] K.W. Beckemeier, Effects of high volumes of fly ash on cement paste, Master's Thesis, Missouri University of Science and Technology: Missouri, USA, 2012.

[5] N. Abdelmelek, and E. Lubloy, "Evaluation of the mechanical properties of high - strength cement paste at elevated temperatures using metakaolin", J. Therm. Anal. Calorim., 2020.

[6] R.F. Feldman, and H. Cheng, "Properties of portland cement-silica fume pastes i. Porosity and surface properties", Cement Concr. Res., vol. 15 , no. 5 , pp. $765-774,1985$.

[http://dx.doi.org/10.1016/0008-8846(85)90141-3]

[7] C. Xiaofeng, G. Shanglong, D. Darwin, and S.L. McCabe, "Role of silica fume in compressive strength of cement paste, mortar, and concrete", ACI Mater. J., vol. 89, no. 4, pp. 375-387, 1992.

[8] M. Kasińska, J. Kempiński, and R. Świerzko, "The consistency of cement pastes and their rheological parameters", Form. Environ. Sci., vol. 15 , no. 3, pp. 71-81, 2017.

[9] F. Bektas, K. Wang, and H. Ceylan, "Use of ground clay brick as a pozzolanic material in concrete", J. ASTM Int., vol. 5, no. 10, pp. 1-10, 2008 .

[10] A.M.S. Mrunalini, and K. Chandramouli, "Experimental study on fresh and hardened properties of concrete by incorporating fly ash, metakaolin and brick powder by partial replacement of cement for M40 grade concrete", Int. J. Adv. Res. Ideas Innov. Technol., vol. 4, no. 3, pp. 1803-1808, 2018.

[11] M.M. Salman, and M.Z. Yousif, "The effect of waste brick powder as cement weight replacement on properties of sustainable concrete", $J$. Eng. Sustain. Dev., vol. 22, no. 2, pp. 116-130, 2018

[http://dx.doi.org/10.31272/jeasd.2018.2.88]

[12] M.S. Shackley, "X-Ray Fluorescence Spectrometry (XRF)", Encycl. Archaeol. Sci, pp. 1-5, 2018.

[13] W. Kurdowski, Cement and Concrete Chemistry., Polish Scientific Publishers PWN: Warsaw, Poland, 1991.

[14] P.C. Lin, S. Lin, P.C. Wang, and R. Sridhar, "Techniques for physicochemical characterization of nanomaterials", Biotechnol. Adv., vol. 32 , no. 4 , pp. 711-726, 2014.

[http://dx.doi.org/10.1016/j.biotechadv.2013.11.006] [PMID: 24252561]

[15] J. T. Orasugh, S. K. Ghosh, and D. Chattopadhyay, Nanofiberreinforced Biocomposites., 2020.

[http://dx.doi.org/10.1016/B978-0-12-819904-6.00010-4]

[16] M. Vippola, M. Valkonen, E. Sarlin, M. Honkanen, and H. Huttunen, "Insight to nanoparticle size analysis-novel and convenient image analysis method versus conventional techniques", Nanoscale Res. Lett., vol. 11, no. 1, p. 169, 2016.

[http://dx.doi.org/10.1186/s11671-016-1391-z] [PMID: 27030469]

[17] Q. Liu, T. Tong, S. Liu, D. Yang, and Q. Yu, "Investigation of using hybrid recycled powder from demolished concrete solids and clay bricks as a pozzolanic supplement for cement", Constr. Build. Mater., vol. 73 , pp. 754-763, 2014.

[http://dx.doi.org/10.1016/j.conbuildmat.2014.09.066]

[18] Z. Ge, Y. Wang, R. Sun, X. Wu, and Y. Guan, "Influence of ground waste clay brick on properties of fresh and hardened concrete", Constr. Build. Mater., vol. 98, pp. 128-136, 2015.

[http://dx.doi.org/10.1016/j.conbuildmat.2015.08.100]

[19] Y. Zhao, J. Gao, G. Liu, X. Chen, and Z. Xu, "The particle size effect of waste clay brick powder on its pozzolanic activity and properties of blended cement", J. Clean. Prod., 2019.

[20] F. Bektas, and K. Wang, "Performance of ground clay brick in ASRaffected concrete : Effects on expansion, mechanical properties and ASR gel chemistry", Cement Concr. Compos., pp. 1-6, 2011.

[21] H. Kabir, R.D. Hooton, and N.J. Popo, "Cement and Concrete Research Evaluation of cement soundness using the ASTM C151 autoclave expansion test", Cement Concr. Res., vol. 136, no. 5, 2020.

[22] R. Walker, and S. Pavía, "Physical properties and reactivity of pozzolans, and their influence on the properties of lime-pozzolan pastes", Mater. Struct. Constr., vol. 44, no. 6, pp. 1139-1150, 2011. [http://dx.doi.org/10.1617/s11527-010-9689-2]

[23] K. Gourav, and B.V.V. Reddy, "Bond development in burnt clay and fly ash-lime-gypsum brick masonry", J. Mater. Civ. Eng., vol. 30, no. 9, pp. 1-10, 2018.

[http://dx.doi.org/10.1061/(ASCE)MT.1943-5533.0002412]

[24] C. Shi, Y. Wu, C. Riefler, and H. Wang, "Characteristics and pozzolanic reactivity of glass powders", Cement Concr. Res., vol. 35, no. 5, pp. 987-993, 2005.

[http://dx.doi.org/10.1016/j.cemconres.2004.05.015]

[25] E. Navrátilová, and P. Rovnaníková, "Pozzolanic properties of brick powders and their effect on the properties of modified lime mortars", Constr. Build. Mater., vol. 120, pp. 530-539, 2016. [http://dx.doi.org/10.1016/j.conbuildmat.2016.05.062]

[26] V.L. Bonavetti, V.F. Rahhal, and E.F. Irassar, "Studies on the carboaluminate formation in limestone filler-blended cements", 
Cement Concr. Res., vol. 31, no. 6, pp. 853-859, 2001 [http://dx.doi.org/10.1016/S0008-8846(01)00491-4]

[27] R.F. Feldman, V.S. Ramachandran, and P.J. Sereda, "Influence of $\mathrm{CaCO} 3$ on the Hydration of $3 \mathrm{CaO} \cdot \mathrm{Al} 2 \mathrm{O} 3 "$, J. Am. Ceram. Soc., vol. 48 , no. 1 , pp. 25-30, 1965.

[http://dx.doi.org/10.1111/j.1151-2916.1965.tb11787.x]

[28] V.S. Ramachandran, and Z.C. Mei, "Hydration kinetics and microstructural development in the 3CaO. AI203-CaSO4. $2 \mathrm{H} 20$ CaCO3-H20 system", Mater. Constr., vol. 19, no. 114, pp. 437-444, 1986.

[http://dx.doi.org/10.1007/BF02472147]

[29] X. Yu, S. Kang, and X. Long, "Compressive strength of concrete reinforced by TiO2 nanoparticles", AIP Conf. Proc., vol. 2036, no. 11, pp. 2-7, 2018.

[http://dx.doi.org/10.1063/1.5075659]

[30] A.A. Aliabdo, A-E. Abd-Elmoaty, and H. Hassan, "Utilization of crushed clay brick in concrete industry", Alex. Eng. J., vol. 53, no. 2, pp. 151-168, 2015

[31] L.G. Li, Z.H. Lin, G.M. Chen, A.K.H. Kwan, and Z.H. Li, "Reutilization of clay brick waste in mortar: Paste replacement versus cement replacement", J. Mater. Civ. Eng., vol. 31, no. 7, pp. 1-12, 2019.

[http://dx.doi.org/10.1061/(ASCE)MT.1943-5533.0002794]

[32] K. Kartini, M.N. Rohaidah, and Z. Zuraini, "Performance of ground clay bricks as partial cement replacement in grade 30 concrete", Int. J. Civil Environ. Struct. Constr. Archit. Eng., vol. 6, no. 8, pp. 362-365, 2012.

[33] "Civil Engineering Forum, Workability of concrete and the factors influencing its value., Montenegro: Podgorica", Available from: https://www.civilengineeringforum.me/workability-of-concrete/

[34] C. Patil, "Lab manual of concrete technology., Sanjay Chodawat Group: New Delhi, India", Available from: http://www.sginstitute .in/Downloads/Civil_Downloads/Manual_ConcreteTech.pdf

[35] P. Bhattarai, Effect of Water Content on Workability of Concrete.,
Pulchowk: Nepal, 2019.

36] H. El-Diadamony, A.A. Amer, T.M. Sokkary, and S. El-Hoseny, "Hydration and characteristics of metakaolin pozzolanic cement pastes", HBRC J., vol. 14, no. 2, pp. 150-158, 2018 [http://dx.doi.org/10.1016/j.hbrcj.2015.05.005]

[37] A.C. Aydin, and R. Gül, "Influence of volcanic originated natural materials as additives on the setting time and some mechanical properties of concrete", Constr. Build. Mater., vol. 21, no. 6, pp. 1277-1281, 2007

[http://dx.doi.org/10.1016/j.conbuildmat.2006.02.011]

[38] K.L. Lin, B.Y. Chen, C.S. Chiou, and An Cheng, "Waste brick's potential for use as a pozzolan in blended Portland cement", Waste Manag. Res., vol. 28, no. 7, pp. 647-652, 2010.

[http://dx.doi.org/10.1177/0734242X09355853] [PMID: 20103570]

[39] H.H.C. Wong, and A.K.H. Kwan, "Packing density of cementitious materials: Measurement and modelling", Mag. Concr. Res., vol. 60 , no. 3, pp. $165-175,2008$.

[http://dx.doi.org/10.1680/macr.2007.00004]

[40] C.A.A. Rocha, G.C. Cordeiro, and R.D. Toledo Filho, "Influence of stone cutting waste and ground waste clay brick on the hydration and packing density of cement pastes", Bracon Struct. Mater. J., vol. 6, no. 4, pp. 661-680, 2013.

[http://dx.doi.org/10.1590/S1983-41952013000400009]

[41] P. Sargent, The development of alkali-activated mixtures for soil stabilisation., Woodhead Publishing Limited, 2015.

[http://dx.doi.org/10.1533/9781782422884.4.555]

[42] J. Shao, J. Gao, Y. Zhao, and X. Chen, "Study on the pozzolanic reaction of clay brick powder in blended cement pastes", Constr. Build. Mater., vol. 213, pp. 209-215, 2019.

[http://dx.doi.org/10.1016/j.conbuildmat.2019.03.307]

[43] X. Sun, Y. Du, W. Liao, H. Ma, and J. Huang, "Measuring the heterogeneity of cement paste by truly distributed optical fiber sensors", Constr. Build. Mater., vol. 225, pp. 765-771, 2019. [http://dx.doi.org/10.1016/j.conbuildmat.2019.07.187]

(C) 2021 Sinkhonde et al.

This is an open access article distributed under the terms of the Creative Commons Attribution 4.0 International Public License (CC-BY 4.0), a copy of which is available at: https://creativecommons.org/licenses/by/4.0/legalcode. This license permits unrestricted use, distribution, and reproduction in any medium, provided the original author and source are credited. 